\title{
Análise dos gases poluentes liberados durante a queima de cerâmica vermelha incorporada com lodo de estação de tratamento de água
}

\author{
(Pollutant gas analysis evolved during firing of red ceramic \\ incorporated with water treatment plant sludge)
}

\author{
V. P. Souza ${ }^{1}$, R. Toledo ${ }^{1}$, J. N. F. Holanda ${ }^{2}$ H. Vargas ${ }^{1}$, R. T. Faria Jr. ${ }^{1}$ \\ ${ }^{\prime}$ Laboratório de Ciências Físicas - LCFIS \\ ${ }^{2}$ Laboratório de Materiais Avançados - LAMAV/GMCer, Universidade Estadual do Norte Fluminense Darcy \\ Ribeiro - UENF, Av. Alberto Lamego 2000, Parque Califórnia, Campos dos Goytacazes, RJ 28013-602 \\ vanessa@uenf.br
}

\begin{abstract}
Resumo
Diante dos problemas ambientais apresentados nas últimas décadas, a preocupação com a emissão gasosa intensificou-se consideravelmente. A indústria de cerâmica vermelha busca alternativas de preservação das matérias-primas naturais utilizadas, as argilas comuns, além de beneficiar o custo de produção. Uma alternativa viável é a incorporação de resíduos industriais à massa argilosa. Isto também contribui para diminuir o impacto ambiental negativo causado pelo lançamento desses resíduos no ambiente. No entanto, pouca atenção tem sido dada à emissão dos gases poluentes liberados durante a etapa de queima desses novos produtos cerâmicos. Neste trabalho, foram preparadas três massas argilosas contendo 0, 15 e 100\% de lodo de estação de tratamento de água (ETA). As composições química e mineralógica do lodo foram determinadas. Corpos cerâmicos preparados por prensagem foram queimados entre 150 e $1100{ }^{\circ} \mathrm{C}$. A emissão dos gases liberados durante a queima foi analisada pela técnica fototérmica. Constatou-se em relação à massa argilosa pura que a incorporação de lodo de ETA provocou um aumento significativo na emissão de $\mathrm{CH}_{4}$ e $\mathrm{CO}_{2}$.
\end{abstract}

Palavras-chave: gases, cerâmica vermelha, lodo de ETA, técnica fototérmica.

\begin{abstract}
In view of the environment problems presented in the last decades, the concern with the gas emissions has been considerably intensified. The red ceramic industry searches alternative of natural raw materials preservation, the commons clays, besides benefiting production costs. A viable alternative is the incorporation of industrial wastes into clayey pastes. This also contributes to decrease the negative environmental impact by release of these wastes in the environment. However, little attention has been given the pollutant gas emissions during the firing step of the new ceramic products. In this work were prepared three clayey pastes containing 0, 15 and 100\% of WTP sludge. The chemical and mineralogical compositions of the ETA sludge were determined. Ceramic pieces prepared by pressing were fired between 150 and $1100^{\circ} \mathrm{C}$. The gas emissions released during firing were analyzed through photothermal technique. It was noted in relation the pure clayey paste, that the addition of WTP sludge provoked a significant increase of $\mathrm{CH}_{4}$ and $\mathrm{CO}_{2}$ emissions.
\end{abstract}

Keywords: gases, red ceramic, WTP sludge, photothermal technique.

\section{INTRODUÇÃO}

A principal matéria-prima bruta utilizada na produção de cerâmica vermelha é a argila comum encontrada na natureza. Por outro lado, a forte demanda no setor de construção civil tem exigido cada vez mais o aumento na produção de produtos de cerâmica vermelha. Uma conseqüência direta dessa situação tem sido o aumento significativo na extração e no consumo de argilas pelo setor. Uma alternativa viável que a indústria de cerâmica vermelha pode aplicar para atenuar o alto consumo de argilas, é o uso de resíduos industriais incorporados às massas argilosas como matériasprimas alternativas. A incorporação quando realizada com sucesso pode melhorar a qualidade do produto final, diminuir o consumo de matérias-primas naturais, diminuir o custo de produção e, principalmente, contribuir para a minimização do impacto ambiental. Além disso, os resíduos industriais e urbanos constituem-se num dos problemas mais preocupantes que a sociedade moderna enfrenta.

Diversos trabalhos têm sido desenvolvidos relacionados à incorporação de resíduos industriais poluentes em massas argilosas para fabricação de cerâmica vermelha. Dentre os vários resíduos investigados destacam-se: resíduos da indústria de rochas ornamentais [1-3], resíduo do setor siderúrgico [4, 5], resíduo de boro [6], resíduo de curtume [7], resíduo da indústria de galvanização [8] e lodos de estação de tratamento de águas $[9,10]$, entre outros. Em geral, esses trabalhos estão relacionados às mudanças estruturais e físicas 
que esses resíduos provocam no produto cerâmico.

$\mathrm{O}$ processamento de materiais cerâmicos, que envolve queima, está associado à liberação de componentes gasosos, quenãotêm sidosuficientemente investigados. Particularmente existe pouca informação na literatura sobre a emissão gasosa durante o processo de queima de cerâmica vermelha [11]. Em geral, a queima de massas cerâmicas argilosas pode liberar concentrações apreciáveis de certos componentes gasosos como: monóxido de carbono (CO), dióxido de carbono $\left(\mathrm{CO}_{2}\right)$, óxidos de nitrogênio $\left(\mathrm{NO}_{\mathrm{x}}\right)$, óxidos de enxofre $\left(\mathrm{SO}_{\mathrm{x}}\right)$, amônia $\left(\mathrm{NH}_{3}\right)$ e metano $\left(\mathrm{CH}_{4}\right)$, que em fortes concentrações prejudicam o meio-ambiente, equipamentos, ferramentas e principalmente a saúde humana [12].

A análise dos gases emitidos associada com os ensaios de lixiviação/solubilidade e os ensaios tecnológicos [13] é a forma mais eficaz de constatar se um produto cerâmico incorporado com resíduo poluente é viável ou não, sob o ponto de vista ambiental e técnico. A busca da qualidade é na atualidade uma questão primordial, sendo impulsionada pelo mercado e regulada pelas exigências técnicas e ambientais e, também, pelo despertar do direito do consumidor.

O objetivo deste trabalho é analisar em escala de laboratório as concentrações dos gases emitidos durante o processo de queima de cerâmica vermelha incorporada com resíduo (lodo) de estação de tratamento de águas.

\section{MATERIAIS E MÉTODOS}

Foram utilizados massa argilosa normalmente empregada na fabricação de cerâmica vermelha no município de Campos dos Goytacazes, RJ, e lodo gerado em estação de tratamento de águas (ETA) localizada na região de Campos dos Goytacazes,RJ, que capta água do Rio Paraíba do Sul. Após sua secagem em estufa, foi destorroado e passado em peneira de malha 20 mesh. A massa argilosa com coloração amarelada devido ao elevado teor de compostos de Fe é predominantemente composta de caulinita, quartzo, mica moscovita, gibsita, goetita e ilita [14].

A composição química do lodo foi determinada por espectroscopia de fluorescência de raios X por dispersão de energia em equipamento EDX Shimadzu. Para a determinação de seus constituintes cristalinos, o resíduo foi submetido à análise de difração de raios X em difratômetro Seifert URD 65 operando com radiação de Co-k e $2 \theta$ variando de $5^{\circ}$ a $70^{\circ}$.

Três massas argilosas foram preparadas: amostra M1 (massa argilosa pura), amostra M2 (argila $+15 \%$ em peso de lodo de ETA) e amostra M3 (100\% de lodo de ETA). As massas foram umidificadas em $8 \%$. Os corpos-deprova retangulares com dimensões $114,5 \mathrm{~mm}$ x $25,4 \mathrm{~mm}$ x $10 \mathrm{~mm}$ foram conformados por prensagem uniaxial a $20 \mathrm{MPa}$. Em seguida foram secos em estufa a $110{ }^{\circ} \mathrm{C}$ até peso constante. A queima foi realizada em um forno tubular resistivo (Maitec FT-1200BI), especial para a detecção de gases. As temperaturas selecionadas foram 150, 300, 450, $550,650,800,950,1050$ e $1100{ }^{\circ} \mathrm{C}$. O ciclo de queima foi $2{ }^{\circ} \mathrm{C} / \mathrm{min}$ até $500{ }^{\circ} \mathrm{C}$ e $4{ }^{\circ} \mathrm{C} / \mathrm{min}$ até $1100{ }^{\circ} \mathrm{C}$ com tempo de permanência, em cada patamar, de 20 min sob fluxo de 3
$\mathrm{mL} / \mathrm{min}$. O resfriamento foi realizado desligando-se o forno e mantendo os corpos-de-prova em seu interior até a temperatura ambiente.

A técnica fototérmica foi usada para a medida das concentrações dos gases [15]. O sistema de detecção e quantificação de gases consistiu de um analisador de gases na faixa do infravermelho (URAS $14 \mathrm{ABB}$ ) conectado ao forno. Na Fig. 1 encontra-se esquematicamente o sistema de funcionamento do URAS-14, onde ocorre a seleção dos comprimentos de onda das espécies sob investigação de uma forma simultânea. Assim, de uma mesma amostra de gases, quantificaram-se os compostos gasosos previamente selecionados, sendo eles $\mathrm{CO}, \mathrm{CO}_{2}$ e $\mathrm{CH}_{4}$.

$\mathrm{O}$ analisador de gases URAS -14 consiste de um emissor

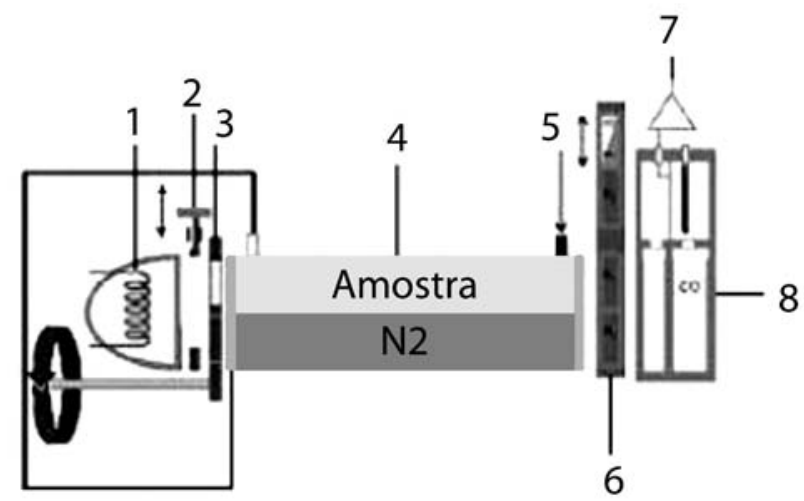

1: fonte térmica (infravermelho); 2: janela óptica; 3: obturador eletromecânico; 4: câmara de gases ( $\mathrm{N}_{2}$ e amostra gasosa); 5: entrada do gás de amostra; 6: janela óptica; 7: amplificador; 8: câmara de análise.

Figura 1: Sistema, esquemático de funcionamento do URAS-14. [Figure 1: Schematic design of the URAS-14 system operation.]

de luz, no qual as emissões alcançam a célula da amostra, após a passagem por um dispositivo (chopper) que faz com que a luz infravermelha passe a ser modulada, além de conter uma célula dividida em 2 compartimentos: uma célula de medida, pela qual a amostra analisada flui e uma célula de referência preenchida com gás inerte, nitrogênio. O detector do analisador consiste de duas câmaras seladas separadas por um diafragma ou membrana capacitiva. Ambas as câmaras são preenchidas com o gás puro (certificado) da espécie química sob investigação. Os feixes de luz que saem da amostra e da célula de referência alcançam independentemente as duas câmaras do detector, provocando uma pressão diferencial que é proporcional à absorção de luz pela amostra. A diferença de pressão é convertida pelo diafragma capacitivo em um sinal elétrico [16].

\section{RESULTADOS E DISCUSSÃO}

Na Fig. 2 é mostrado o difratograma de raios $X$ do lodo de ETA. Foram identificados os picos de difração característicos das fases cristalinas referentes a quartzo $\left(\mathrm{SiO}_{2}\right)$, gibsita $\left(\mathrm{Al}(\mathrm{OH})_{3}\right)$, caulinita $\left(\mathrm{Al}_{2} \mathrm{O}_{3} \cdot 2 \mathrm{SiO}_{2} \cdot 2 \mathrm{H}_{2} \mathrm{O}\right)$, ilita $\left.{ }^{2}\left(\mathrm{~K}_{3} \mathrm{H}_{3} \mathrm{O}\right) \mathrm{Al}_{2} \mathrm{Si}_{3} \mathrm{AlO}_{10}^{3}(\mathrm{OH})_{2}\right)$ e calcita $\left.{ }^{2} \mathrm{CaCO}_{3}^{3}\right)^{2}$. 


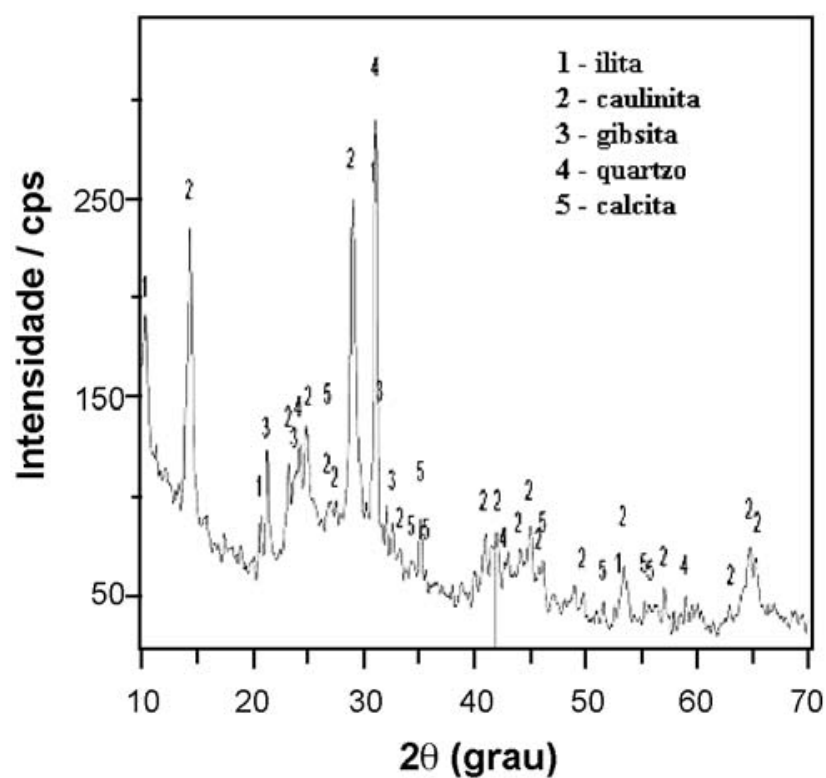

Figura 2: Difratograma de raios $X$ do lodo de ETA.

[Figure 2: X-ray diffraction pattern of the water treatment plant sludge.]

A composição química do lodo de ETA estudado está apresentada na Tabela I. O lodo de ETA apresenta composição química semelhante à das argilas comuns usadas no Pólo Ceramista da região de Campos dos Goytacazes, RJ, para fabricação de tijolos, blocos cerâmicos e telhas. As argilas dessa região são provenientes de sedimentos quaternários (recentes) originados de processo de decantação de material sílico-argiloso da carga de suspensão, após eventos de enchentes do rio Paraíba do Sul. Por causa dessa semelhança química decidiu-se analisar a emissão gasosa em corpos-deprova com 100\% de lodo de ETA (amostra M3).

Do ponto de vista químico o lodo de ETA é constituído basicamentepor $\mathrm{SiO}_{2}, \mathrm{Al}_{2} \mathrm{O}_{3} \mathrm{eFe}_{2} \mathrm{O}_{3}$, quejuntos correspondem a cerca de $82,77 \%$. O teor de $\mathrm{SiO}$ está associado à estrutura cristalina dos argilominerais, como por exemplo, caulinita, ou ainda, apresentar-se na sua forma livre como quartzo. $\mathrm{O}$ teor de alumina está associado à estrutura dos argilominerais, ou ainda, ao hidróxido de alumínio (gibsita). O elevado teor de ferro pode estar presente na forma de óxidos ou hidróxidos de difícil identificação por difração de raios X por apresentarem estruturas pouco cristalinas, ou ainda por estar em substituição parcial do alumínio na rede cristalina da caulinita [17]. A perda ao fogo do lodo de 14,50\% está associada à remoção de água fisicamente adsorvida, desidratação de hidróxidos de alumínio e ferro, decomposição de matéria orgânica, desidroxilação dos argilominerais (caulinita e ilita) e decomposição de carbonato de cálcio, conforme dados apresentados [18].
As massas cerâmicas incorporadas com resíduo poluente obrigatoriamente estão sujeitas à legislação ambiental. Uma grande preocupação é com relação às emissões gasosas durante a fabricação do produto cerâmico, especialmente durante a etapa de queima. As emissões gasosas podem causar impacto ambiental com o aumento significativo da poluição do ar. No presente trabalho foram analisadas as concentrações de $\mathrm{CO}_{2}$, $\mathrm{CO}$ e $\mathrm{CH}_{4}$. O monóxido de carbono é um gás mais leve do que o ar e altamente tóxico, que causa poluição do ar e efeitos severos a saúde humana. O dióxido de carbono constitui-se na atualidade uma grande preocupação da sociedade moderna, pois além de contribuir para a poluição do ar contribui, também, fortemente para o efeito estufa. O metano é um gás mais nocivo ao efeito estufa do que o dióxido de carbono.

Nas Figs. 3 e 4 estão mostradas, respectivamente, as emissões de $\mathrm{CO}_{2}$ e $\mathrm{CO}$ durante o processo de queima de cerâmica vermelha. A incorporação do lodo de ETA resultou em uma elevação da concentração dos gases carbônicos para o meio ambiente. Verificou-se, por exemplo, que a concentração de $\mathrm{CO}_{2}$ emitido pela amostra $\mathrm{M} 2$ foi cerca de dez vezes maior do que a concentração em relação à amostra M1, devido a concentração de matéria orgânica presente na amostra. Para a faixa de temperatura de queima investigada, as maiores emissões ocorreram entre aproximadamente 200 e $600{ }^{\circ} \mathrm{C}$ com pico máximo em torno de $450{ }^{\circ} \mathrm{C}$. As origens dessas emissões estão relacionadas, fundamentalmente,

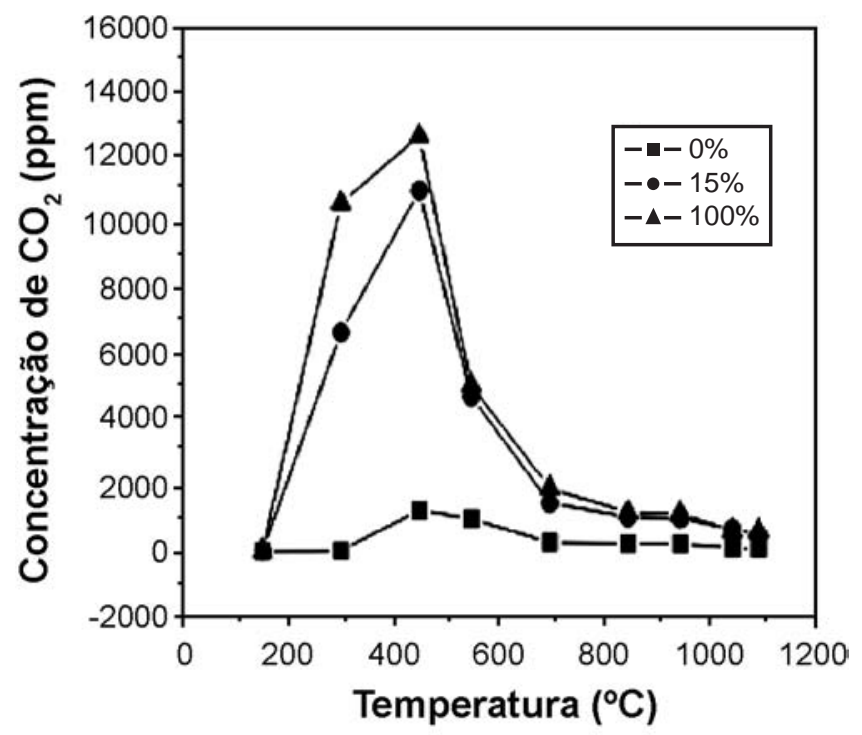

Figura 3: Emissão de $\mathrm{CO}_{2}$ em função da temperatura de queima. [Figure 3: $\mathrm{CO}_{2}$ profile as a function of the firing temperature.]

Tabela I - Composição química do lodo de ETA (wt.\%).

[Table I - Chemical composition of the water treatment plant sludge.]

\begin{tabular}{cccccccccccc}
\hline $\mathrm{SiO}_{2}$ & $\mathrm{Al}_{2} \mathrm{O}_{3}$ & $\mathrm{Fe}_{2} \mathrm{O}_{3}$ & $\mathrm{TiO}_{2}$ & $\mathrm{~K}_{2} \mathrm{O}$ & $\mathrm{MgO}$ & $\mathrm{P}_{2} \mathrm{O}_{5}$ & $\mathrm{CaO}$ & $\mathrm{MnO}$ & $\mathrm{Na}_{2} \mathrm{O}$ & $\mathrm{PF}$ \\
\hline 37,03 & 32,69 & 13,05 & 1,13 & 0,60 & 0,39 & 0,36 & 0,10 & 0,10 & 0,06 & 14,50 \\
\hline
\end{tabular}




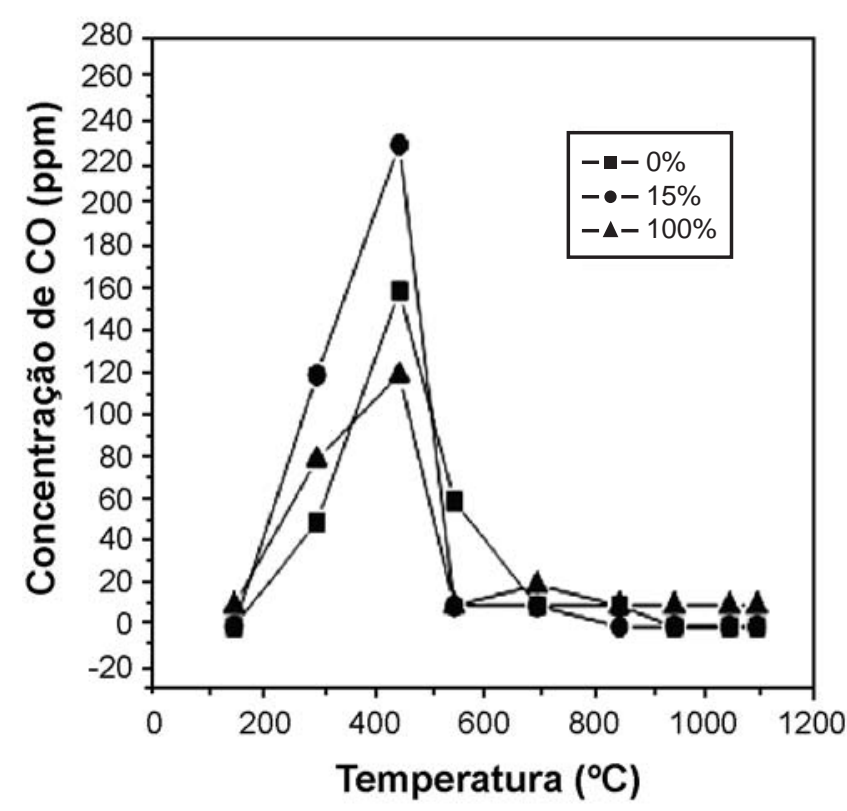

Figura 4: Emissão de CO em função da temperatura de queima. [Figure 4: CO profile as a function of the firing temperature.]

à decomposição da matéria orgânica. De fato, os lodos de estação de tratamento de águas são, geralmente, ricos em matéria orgânica [10]. É importante destacar que o vapor de água resultante da desidratação de hidróxidos e, principalmente, da desidroxilação da caulinita tende a aumentar a atividade dos componentes gasosos [18, 19]. Observa-se, ainda que em torno de $700{ }^{\circ} \mathrm{C}$ a emissão de $\mathrm{CO}_{2}$ é maior para as amostras contendo lodo de ETA. Isto pode estar relacionado com a decomposição de calcita $\left(\mathrm{CaCO}_{3}{ }^{\circledR}\right.$ $\mathrm{CaO}+\mathrm{CO}_{2}$ ) presente no lodo de ETA (Fig. 2). No perfil

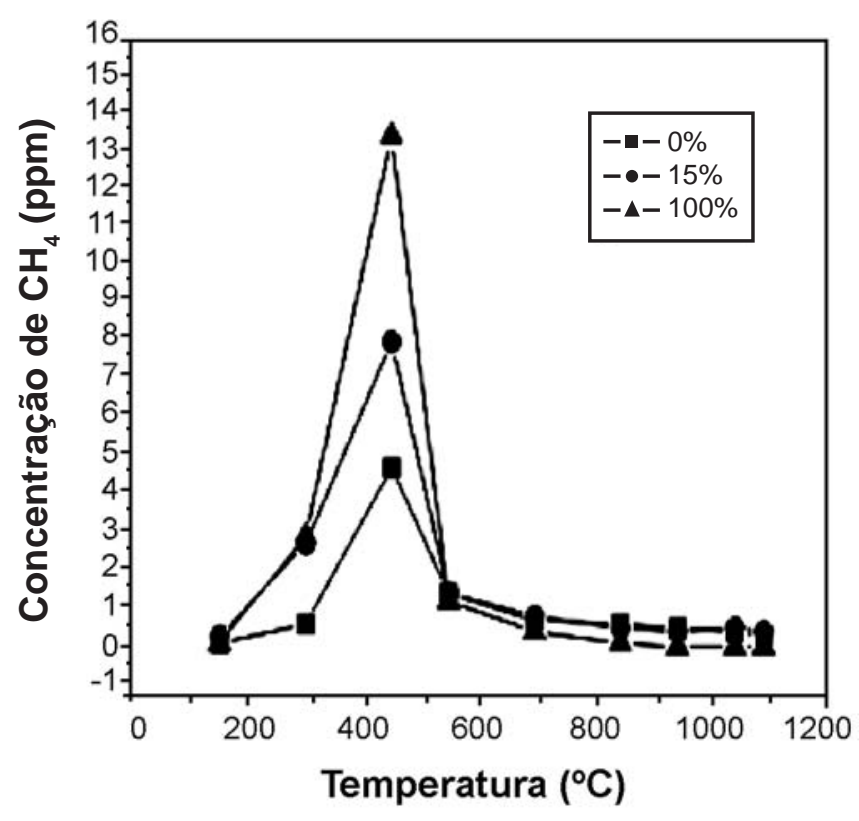

Figura 5: Emissão de $\mathrm{CH}_{4}$ em função da temperatura de queima. [Figure 5: $\mathrm{CH}_{4}$ profile as a function of the firing temperature.] do CO é importante destacar as condições atmosféricas presentes no forno, durante a queima. Quando a atmosfera está rica em oxigênio ocorre a combustão completa, havendo uma maior liberação de $\mathrm{CO}_{2}$ e o caso contrário tende a diminuir o $\mathrm{CO}_{2}$ e aumentar a liberação de CO. Esta, possivelmente, é a justificativa para o comportamento do perfil de concentração de CO das amostras.

Na Fig. 5 encontram-se as emissões de $\mathrm{CH}_{4}$ na faixa de temperatura de queima estudada. $\mathrm{O}$ lodo de ETA contribuiu para aumentar a emissão de $\mathrm{CH}_{4}$ para o meio ambiente. Em torno de $480{ }^{\circ} \mathrm{C}$ ocorreu uma liberação mais intensa devida, provavelmente, ao ápice da desidroxilação da caulinita, favorecendo à abertura de poros que permitiu uma maior liberação dos gases provenientes da queima da matéria orgânica encontrada significativamente na amostra [18].

\section{CONCLUSÕES}

O lodo de ETA efetivamente contribui para aumentar as emissões dos gases $\mathrm{CO}_{2}$, $\mathrm{CO}$ e $\mathrm{CH}_{4}$ durante o processo de queima de cerâmica vermelha, visto que o CO é conseqüência das condições atmosféricas do forno, ou seja, se estiver rico em oxigênio a concentração de $\mathrm{CO}_{2}$ será bem maior que a do CO. Portanto, há uma grande preocupação sob o aspecto ambiental em avaliar a aplicação deste resíduo na produção em larga escala de cerâmica vermelha.

\section{AGRADECIMENTOS}

À FAPERJ e ao CNPq pelo suporte financeiro.

\section{REFERÊNCIAS}

[1] H. F. Mothé Filho, H. Polianov, E. V. Barroso, C. G. Mothé, Thermochim. Acta 392-393 (2002) 47-50.

[2] R. R. Menezes, H. S. Ferreira, G.A. Neves, H. C. Ferreira, Cerâmica 48, 306 (2002) 92-101.

[3] A. M. Segadães, M. A. Carvalho, W. Acchar, Appl. Clay Sci. 30, 1(2005) 42-52.

[4] E. A. Domingues, R. Ullmann, Appl. Clay Sci. 11 (1996) 237-5249.

[5] G. E. Oliveira, J. N. F. Holanda, Waste Manag. Res. 22 (2004) 358-363.

[6] T. Uslu, A. I. Arol, Waste Manag. 24 (2002) 47-50.

[7] T. Basegio, F. Berutti, A. Bernardes, C. P. Bergmann, J. Eur. Ceram. Soc. 22, 13 (2002) 2251-2259.

[8] J. M. Magalhães, J. E. Silva, F. P. Castro, J. A. Labrincha, J. Hazardous Mater. 106, 2-3 (2004) 139-147.

[9] E. M. S. Oliveira, V. G. Sampaio, J. N. F. Holanda, Ind. Ceram. 26 (2006) 23 -28.

[10] S. R. Teixeira, S. A. Souza, N. R. Souza, P. Aléssio, G. T. A. Santos, Cerâmica 52, 323 (2006) 215-220.

[11] R. Toledo, D. R. Santos, R. T. Faria Jr., J. G. Carrió, L. T. Auler, H. Vargas, Appl. Clay Sci. 27 (2004) 151-157. [12] D. J. Morgan, Appl. Clay Sci. 8, 2-3 (1993) 81-89.

[13] J. Alexandre, F. Saboya, B. C. Marques, M. L. P. Ribeiro, C. Salles, M. G. Silva, M. Sthel, S. L. T. Auler, H. 
Vargas, The Analyst 124 (1999) 1209.

[14] E. M. S. Oliveira, Tese de Doutorado, Universidade Estadual do Norte Fluminense, Campos dos Goytacazes, RJ (2004).

[15] R. T. Faria Jr., M. P. P. Castro, J. Alexandre, R. Toledo, L. O. Carneiro, W. S. Ribeiro, M. S. Sthel, D. U. Schramm, H. Vargas, J. Phys. IV 125 (2005) 837-840.

[16] J. A. P. Lima, Tese de Doutorado, Universidade Estadual do Norte Fluminense, Campos dos Goytacazes, RJ (2001).
[17] R. S. T. Manhães, L. T. Auler, M. S. Sthel, J. Alexandre, M. S. O. Massunaga, J. G. Carrió, D. R. Santos, E. C. Silva, A Garcia-Queiroz, H. Vargas, Appl. Clay Sci. 21 (2002) 303-311.

[18] E. M. S. Oliveira, S. O Machado, J. N. F. Holanda, Cerâmica 50, 316 (2004) 324-330.

[19] D. R. dos Santos, R. Toledo, R. T. Faria, Jr., J. G. Carrió, M. G. da Silva, L. T. Auler, H. Vargas, Rev. Sci. Instrum. 74, 1 (2003) 663-666.

(Rec. 25/10/2007, Rev. 29/02/2008, Ac. 04/04/2008) 